\title{
Research on Foshan Atmospheric Environment Quality Control as An Economically Developed City
}

\author{
Wei Xie ${ }^{1, a}$ \\ ${ }^{1}$ Legal College, Guangdong university of finance \& economics, Guangzhou, 510120,China \\ aemail: 18927527246@163.com
}

Keywords: Atmospheric Environment; Targets Assessment; Restructuring

\begin{abstract}
In recent years, Foshan has made significant progress in atmospheric quality. At the same time, Foshan's economy maintains a rapid development. Why Foshan can keep coordinated development of economy and the environment? It is very difficult for the atmospheric environment quality controll. This paper mainly focuses on the good practices which Foshan has taken.
\end{abstract}

\section{Introduction}

As the third largest city in Guangdong province, Foshan is the historic and cultural city, the hometown of Bruce Lee and Wong Fei-Hung, the economic powerhouse of the Pearl River Delta(PRD). After more than 30 years of development, Foshan has become a famous manufacturing city which has industry-led and coordinated development of three major industries.

\section{Foshan Air Pollution and Comprehensive Governanve}

Air is the necessary factor for the humankind and other creature to survive.[1]However, Foshan is faced with the serious air pollution. Foshan is the Key contaminated areas in PRD, particularly for VOCs and PM2.5. From the statistical data, the average polluted days are 151. In the last half year of 2007,according to the PRD air quality report, the air quality in nearly thirty percent days was not up to National secondary standard of ambient air quality standard. Foshan is the worst air quality in PRD only judged by the two indicators of sulfur dioxide and inhalable particle.

Foshan has taken the effective measures to air pollution. In 2009, according to the PRD air quality monitoring report, the annual means of sulfur dioxide, nitrogen dioxide and inhalable particle separately decreased $46 \%, 12 \%$ and $17 \%$. Foshan city government made the comprehensive improvement for the ceramics industry in 2009, which resulted in the sharp fall of inhalable particle. In 2012, Foshan air quality is good generally, the good days (API $I \leq 100$ ) accounted for $97 \%$ of the whole year round. The annual average concentration of SO2,NO2 and PM10 were up to National secondary standard of ambient air quality standard. In 2003, the good air quality days of Foshan which attained to or prevailed over the second standard got up to 242, at the same time, China's fog and haze is so serious throughout the country.

\begin{tabular}{|c|c|c|c|c|c|}
\hline year & 2008 & 2009 & 2010 & 2011 & 2012 \\
\hline Days of API $\leqslant 100$ & 362 & 355 & 354 & 357 & 354 \\
\hline $\begin{array}{c}\text { Days of API } \leqslant 100 \\
\text { Proportion to Year Round }(\%)\end{array}$ & 98.9 & 97.3 & 97 & 97.8 & 97 \\
\hline Year Round* $80 \%$ & $\begin{array}{c}292 . \\
8\end{array}$ & $\begin{array}{c}292 . \\
0\end{array}$ & $\begin{array}{c}292 . \\
0\end{array}$ & $\begin{array}{c}292 . \\
0\end{array}$ & 292.8 \\
\hline $\begin{array}{c}\text { Dust Fall Quantity } \\
\text { (Tons per square kilometer, a } \\
\text { month) }\end{array}$ & 5.74 & 4.50 & 4.66 & 4.10 & --- \\
\hline Indicator Requirement & \multicolumn{5}{|c|}{$\begin{array}{c}\text { Days of API } \leqslant 100 \text { in Year Round } \\
\geqslant 80 \% \text { of Year Round }\end{array}$} \\
\hline
\end{tabular}

Figure 1 Foshan API Index Between 2008---2012 
With the same pace of air quality governance, Foshan economic development maintains the rapid pace. Economic gross continually increases. According to Foshan statistical bulletin for national economic and social development, Foshan GDP average growth rate per annum was up to $18.95 \%$ from 2003 to 2006 , and got to $10.28 \%$ from 2007 to 2013 .

In both 2010 and 2011, Foshan GDP ranked the eleventh in all the cities of the country. In 2013, Foshan GDP ranked the third in all the cities of Guangdong province.

Foshan economic development pattern has become the representative of China reform, at the same time, its air quality control mode should also stand for the China city air pollution governance because it realized the coordination development between economic and environment.

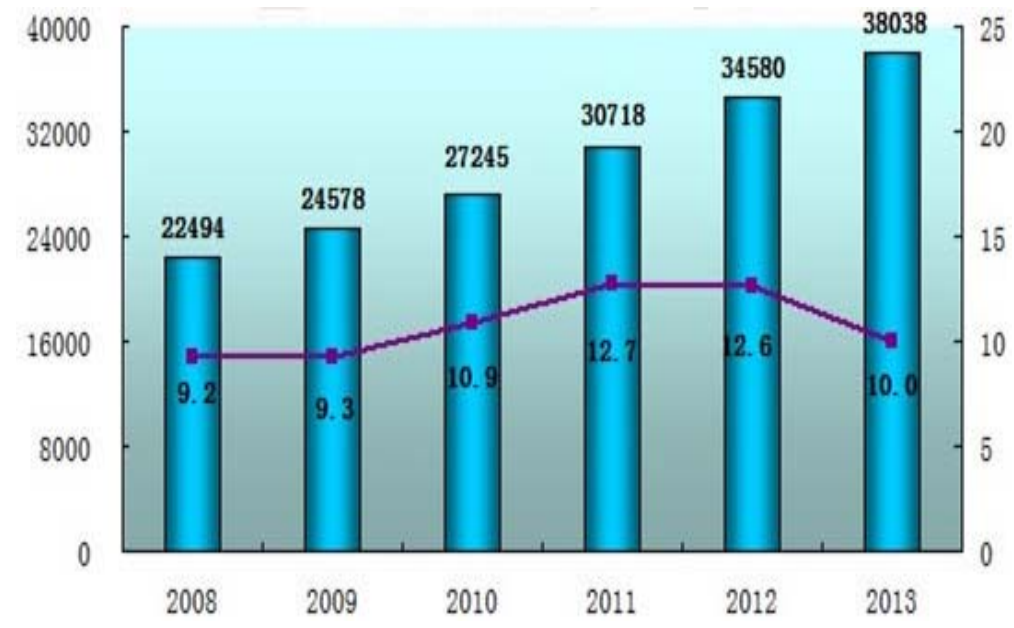

Figure 2 Foshan Urban Residents Disposable Income Growth of 2008-2013

\section{Foshan Air Quality Controlling Methods}

As a developed city, Foshan can pay more attention to city atmospheric environment quality. However, Foshan did not copy the air quality management theory. It has taken the suitable air quality management methods on the basis of Foshan specific circumstance.

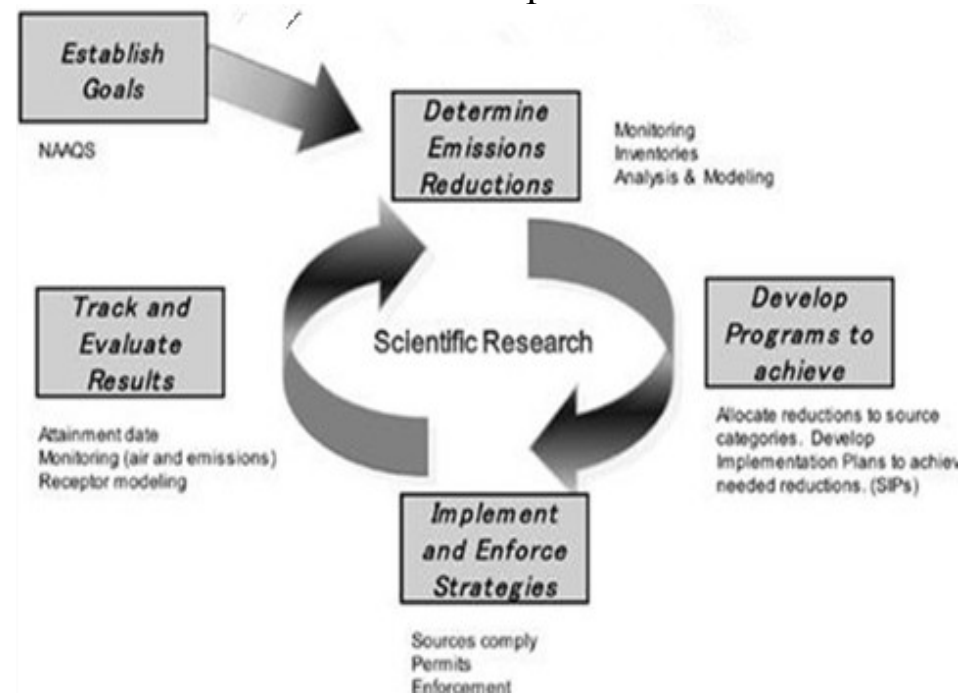

Figure 3 Air Quality Management Theory[2]

\section{Practical Air Quality Controlling Target}

Since 2003, Foshan has determined environment control target and energy consumption decreased target each year, and Implement assessment in the next year. For example, Industrial Pollution Sources fully compliance was put as the target in 2003. Unit production of gross energy consumption must be decreased by $4.5 \%$ than last year in 2006. At the same time, assessment in 
2009 was to decrease GDP energy consumption, main pollutants, and COD continually in order to complete expected objectives and tasks of last year. Not only the micro-targets, but also the macro-targets are also determined. Such as, Foshan has determined the eco-city construction planning(2012-2020) since 2012. The micro-targets and the macro-targets establish a viable targets together.

\section{The Most Stringent Environmental Assessment Methods And Accountability System}

Foshan set up environment protection committee in November 2011, whose members consisted of each unit leaders. In August 2013, the most stringent Environment Responsibility Assessment Methods was published. The methods integrated multiple environmental protection accountability system, defined the committee as leading execution, so as to avoid the drawbacks of multiple assessment.

Firstly, it vigorously promotes public awareness of the illegal discharge of industrial waste gases, smoky vehicles, illegal disposal of industrial solid waste and rewarded those reported, encourages the media to expose the environmental pollution. To those exposure of pollution, district-level environment protection agencies must publish the processing results to the public through the website or twitter in seven days.

Secondly, assessment methods are classified as quarterly test and annual exam. The test or exam includes lots of ways to get score, such as on-site inspection verification, expert evaluation, interactive media, third-party evaluation to quantify, and so on. Quarterly test mainly points to engineering projects, and annual exam mainly points to completion of the indicators and degree of environmental quality improvement. Each district annual exam gets the last score on the basis of each indicators score and the average scores of the quarterly test in that year. For the problems being identified, the committee should instruct the assessment unit for rectification. If the rectification is not in place or failed to complete in time, it will be brought to supervise by the committee.

Thirdly, environmental accountability assessment fund system is established. Each district pays 2 million Yuan as annual assessment fund, and 1 million Yuan as quarterly assessment fund. For those qualified by assessment, the assessment fund should be turned to the next year, or the next season. Otherwise, the fund will be deducted and included the special Municipal Environmental Protection accountability assessment account.

\section{Construction of Eco-Industrial Park}

Foshan has planned to set up eight key eco-industrial park in order to avoid the scattered enterprises sewage separately that is not conducive to regulatory. These parks include most of the Foshan enterprises. For example, Foshan High-tech Zone focus on the development of electronic information, electromechanical integration, precision manufacturing, non-ferrous metal processing, new materials, biotechnology, eco-ceramics, green appliances and other high-tech companies industries. Currently, it is the high level of industrialization in the region, and includes more than 160 large-scale enterprises. There are 17 enterprises whose annual output value is over one hundred million yuan, including more than 10 enterprises of Fortune 500 companies. The completion and use of the industrial parks makes Foshan can centralize supervision, so as to greatly reduce the cost of administrative enforcement of atmospheric pollution, and greatly contribute to the effects of air pollution control.

Optimize the industrial layout. For example, Nanhai District of Foshan City fully implements centralized production, centralized pollution control for textile printing and dyeing industry. According to the distribution of environmental capacity, the textile printing and dyeing industry production bases are concentrated on building in Xiqiao Technology Industrial Park, which can centralize both heating and pollution control. By focusing on all kinds of polluting industries in the industrial park, the total pollutant emissions are effectively reduced, and a better quality of atmospheric environment is achieved. 


\section{Full Control of The Traditional Key Industries, Strict Clean Production}

Foshan traditional industries pollution discharge accounts for relatively large proportion to the total pollution emission. For example, the four key industries of Nanhai District, such as electricity, ceramics, textile and aluminum, discharge the sulfur dioxide that accounts for over $90 \%$ of the region's total emissions of sulfur dioxide[3]. So it is the key for the important industries and enterprises to decrease the emission. Foshan has taken energy conservation and emission reduction to force the corporate restructuring and upgrading. Cleaner Production is fully implemented for ceramics industry, power industry, textile industry, cement industry, and so on.

For example, the ceramics industry mainly adopts the following methods:

Firstly, the cleaner production technologies and equipment are effective used. Such as, Large-size ceramic plate technology is the entire improvement and innovation to ceramic production equipment. The raw material consumption can be reduced by about $70 \%$, electricity consumption per square meter can be decreased by about $25 \%$, and reduction in fuel consumption by about $70 \%$, compared with the current ceramic tiles. To improve product packaging efficiency, reduce labor intensity and number of personnel, the automatic balers are commonly used. To overcome high decorative operating costs of the traditional ceramic, low color glaze utilization, monotonous pattern and other shortcomings, inkjet printing technology is extensively used. Exterior-wall tile-free-pad-firing technology can reduce energy consumption by $10-15 \%$ of the firing.

Secondly, spray desulphurization and dust removal, waste heat utilization, high power motor frequency conversion, workshop dust control, resource comprehensive utilization and other innovations are widely used, so that makes the ceramic industry achieve significant results in energy conservation, consumption abatement and emission drop.

Thirdly, the ceramic cleaner production is effectively connected with Circular Economy and resource comprehensive utilization. The ceramic waste is used for production of ceramic tiles, the current incorporation of ceramics waste can reach by $40 \%$ of the total waste, some of which can reach by more than 70 percent. As a result, it is solved for the ceramic waste difficult to deal with, raw material is saved, production cost is reduced, and the enterprise sustainable development is promoted. Nowadays, there are 58 Foshan ceramic enterprises to obtain the honor of Guangdong clean production enterprises, which accounts for $87 \%$ of the total Guangdong cleaner production corporations.

\section{Speeding Up The Adjustment of Industrial Structure and Energy Structur, Reducing Energy Consumption}

Foshan is a large manufacturing city, and also a high energy consumption city. For a long time, the industrial structure and energy consumption structure of Foshan is not conducive to atmosphere quality control. So Foshan carries out the deep and extensive structural adjustment of industrial structure and energy consumption.

Firstly, Foshan vigorously promotes emission reduction for projects, structural and regulatory emissions reduction, improves the high energy-consuming and high-polluting industries structure, such as small thermal power, ceramics, cement, glass, aluminum casting, etc. At the same time, Promote industry to upgrade, accelerate coal, heavy oil-fired, wood-fired boiler to be eliminated, promote large-scale coal-fired industrial boiler to take further desulfurization and denitrification measures, force the high-pollution, high energy-consumption projects to be closed, ended, incorporated or transferred to other industries. 1868 boilers in Foshan have been controlled (or eliminate), that completion rate is over $80 \%$. More than 400 ceramic enterprises have been transformed since 2007, but there are only 60 companies are retained, all of which achieve cleaner production and production process reengineering. Currently, the city focuses on gathering headquarters, exhibition, research and development, logistics and information base for ceramic industry. As a result, when the ceramic production decreases by $40 \%$, the output value and revenue increases by $33 \%$, energy consumption decreases by $25 \%$, and sulfur dioxide emissions by $20 \%$ [ 4 ]. 
Secondly, in order to adjust the energy structure, Foshan promotes greatly cleaner energy, increases the proportion of natural gas, liquefied petroleum gas, electricity and other clean energy with little pollution or no pollution to environment, reinforces the management of high-polluting fuels restricted areas, takes central heating and other methods to reduce energy consumption. In August 2013, the natural gas pipeline network achieves the city's "one network". Then in the next 5 years, Foshan natural gas consumption will reach 3 billion cubic meters, equivalent to one million cars reductions in annual emissions. Foshan Central Heating Plan (2014-2020) is published in 2014, which requires that centralized heating source point layout would be carried out in the main industrial parks and industrial clusters to achieve regional heat, electricity, steam and other end-use energy demand efficient cogeneration so as to meet the growing enterprise heat, electricity, steam load demand.

\section{Vigorously Develop Green Transportation}

By the end of 2013, there were 135.84 million civilian cars in Foshan. Motor vehicle has become the main emission sources to affect the atmospheric environmental quality.

Firstly, Motor vehicle environmental labeling system is carried out. The high-pollution and highemission cars are progressively restricted to pass. The environmental label must be issued to those first registrated in Foshan City, as well as qualified motor vehicle by regularly environmental inspection. Among them, those reach to the standards of issuing green environment inspection qualified label by emissions testing, and have the appropriate technical measures to control vehicle emissions, should be approved and issued with green environment inspection qualified label. Otherwise, those should be issued with yellow environment inspection qualified label. For those high-pollution vehicles without environment inspection qualified label, they will be gradually forbidden or limited to pass through in four stages from August 1, 2010.

Secondly, put vehicle oil improvement as the starting point, strictly control high-pollution vehicles, encourage new-energy vehicles to develop quickly. Especially, upgrading the quality of vehicle oil is the key to reduce motor vehicle pollution. Foshan has implemented oil quality upgrading twice in three years, and led to push Guangdong IV gasoline. At the same time, serious pollution emission vehicles and smoky vehicles must be compulsory retirement, be encouraged early retirement, or be turned outward and be taken other stringent measures. Those early retirement of the serious pollution emission vehicles and reporting smoky vehicles should be given reward.

New-energy vehicles will be vigorously supported, the demonstration models of new-energy bus are identified, the infrastructure and other supporting services are also improved. Such as, for bus companies to buy LNG buses, district-level government should give allowance of not less than 10,000 yuan /vehicles.

\section{Conclusion}

After the hard work, Foshan have got the good result. According to the government work report of Foshan city, PM2.5 has decreased by 15\%, and PM10 decreased by $10 \%$ in 2014[5]. Foshan experience proves that the coordination between economy and environment. can be realized by hard work. It is the key for the government to take the effective measures, and combine with the local conditions so as to solidly advance. Some of the control methods of Foshan atmospheric environment quality should have promotional value, such as the reforming and upgrading of the ceramic industry. However, there are lots of problems for Foshan atmospheric environment quality control needed to be improved, such as PM2.5 and O3 in Foshan is still so serious that neither can Reach the 2012 National Ambient Air Quality Standards. It is obvious that new problems must be resolved continuously for Foshan air quality control as its economy constantly increases. 


\section{Acknowledgement}

In this paper, the research was sponsored by the Soft Science Research Project of Guaongdong Province (Project No. 2014A070703057) and the Twelvth Five-Year Plan Project of Guaongdong Philosophy and Social Science (Project No. GD13CFX04).

\section{References}

[1] Depei, Han. Environment protection laws course[M].Beijing: Law Press China,2012.

[2] John, Bachmann. Will the circle be unbroken: a history of the U.S. National Ambient Air Quality Standards[J].Journal of the Air \& Waste Management Association, 2007( 57) 654.

[3] Mei, li. etc. Research of Foshan Nanhai District atmospheric environment quality change analysis and control[J].Environment Science and Management,2007(12)25.

[4]Yudi, Duan. Ceramic industry's transformation and upgrade pulling Foshan economy up[N].Shenzhen Commercial Newspaper,2012(12)A15.

[5] Luyi. Foshan government work report[N].Foshan Daily,2015-2-16. 